\title{
Ensuring stable quality of ground parts by monitoring the process system parameters
}

\author{
Elmar Yagyaev ${ }^{1, *}$, and Boris Shron ${ }^{2}$ \\ ${ }^{1}$ Crimean Engineering and Pedagogical University, Russian Federation \\ ${ }^{2}$ Sevastopol State University, Sevastopol, Russian Federation
}

\begin{abstract}
The paper proposes a system for monitoring surface wheel-grinding by analyzing the dynamic alterations in output variables and the process system state parameters. It analyzes the intervals of the process system state parameter interrupts. State space analysis was employed to describe the behavior of the grinding process system. The dependencies obtained enable a complete description of how the system behaves at any interval of the main interrupt period. The analysis of such behavior is reduced to sequential calculation of its parameters at times $\mathrm{t}_{1}, \mathrm{t}_{2}, \ldots, \mathrm{t}_{i}$ at interrupt intervals $\mathrm{T}_{1}, \mathrm{~T}_{2}, \ldots, \mathrm{T}_{N}$. The proposed state space analysis method enables an independent evaluation of output perturbations. Besides, by analyzing the dependencies we had obtained, we concluded that for such evaluation, one would have to calculate not only the absolute values of output variables, but also their first and sometimes even second derivatives.
\end{abstract}

\section{Problem statement}

One current trend in mechanical engineering is that assembling joints are becoming considerable more accurate. This necessitates better quality and performance of finishing machining. Metal machines and complexes are equipped with highly efficient controllable drives, special information systems and other functional devices with improved performance. More and more automated equipment comes in use with every year. Analysis of the existing production facilities shows that automated equipment is only used to 70 or 80 percent of its capacity when it comes to cutting and grinding operations.

Let us analyze the reasons why automated equipment is used under-efficiently. When operating conventional machines, operators rely on their observation and operation experience to adjust the cutting parameters. One can machine a shaft in 30 or 40 seconds using a conventional machine, while it takes 100 to 120 seconds when using a CNC machine. This is due to the considerable alterations in the process system state that occur in machining. To ensure the specified quality as well as the stability of output variables, operations are configured for the worst system state.

As a rule, automated systems are coupled with the existing process engineering and control principles without reconsidering and improving the latter. The process is designed once and for all and is usually subject to no alterations over the entire production of a product whereas alterations occurring in the process system are ignored. Operations result in considerable alterations in the accuracy and stiffness properties of machines; the physical and chemical properties of the cooling lubricant may also considerable alter between replacements, and so do the environmental temperatures, the diameter of the grinding wheels, and the condition of their applied surface. Each workpiece has specific properties.

A relevant problem of material cutting theory consists in studying the improvements in performance achieved by monitoring the machining process, i.e. by analyzing the dynamic alterations in the output variables and the process system state parameters. Theoretical and experimental studies show that automated grinding operations can be performed 20 to 25 percent more efficiently; besides, such studies help stabilize the quality of final products.

Despite a significant amount of known research, automated grinding machines are not utilized to their full capacity. This is due to the great impact process system parameters, altering during the machining process, have on both performance and quality. When mounting a new workpiece on the machine, the system assumes a new initial state that is different from the preceding one. To ensure the required quality while keeping high performance in grinding operations, one has either to stabilize the state of the system or to control the process by means of the diagnosis data that factor in the alterations in the process system. When CNC-machining a workpiece, the second approach requires an evaluation of alterations in the process system parameters.

\section{Literature review}

We have analyzed papers on grinding operations and found out that the best theoretical descriptive models are proposed in [1-4]; if appropriately refined, they can factor in the multiplicity of factors affecting the output

\footnotetext{
* Corresponding author: elmar1875@gmail.com
} 
variables and enable the monitoring of the dynamic alteration in the system parameters.

Modern machine control systems provide for inprocess adjustments, which, however, require diagnostic data on the current state in the system and model parameters, as well as a link of the state parameters to the control parameters and the output variables.

The goal hereof is to substantiate the possibility of ensuring a stable quality of ground parts by monitoring the parameters of the process system.

Monitoring and diagnosis methods used in grinding are based either on evaluating the state parameters by using complex diagnosis equipment during a halt, or by analyzing the results of measuring the machined surface quality parameters and some of the process parameters (cutting forces, acoustic emissions, etc.). Both options are not suitable for automated production systems because they enable neither an unambiguous identification of the altered process system parameters nor any prediction of how the system could behave further.

\section{Statement of the main material}

The cutting process alters the parameters of both the process system and the object produced. Given this feature of cutting operations, represent the link of the output variables to the input ones and the state parameters as a function

$$
Y_{j}(t)=F_{j}\left(X_{j} ; Z_{j}(t) ; U_{j}(t) ; \Omega(t)\right),
$$

where $Y_{j}(t)$ is the vector of output variables in the $j$ th cycle at time $t ; X_{j} i s$ the vector of input variables; $Z_{j}(t)$ $i s$ is the vector of the process system state parameters in the $j t h$ cycle at time $t ; U_{j}(t)$ isthe corresponding vector of control effects; $\Omega(t)$ is the vector of perturbation effects.

$$
Y_{j}(t)=\left(r ; \varepsilon ; T ; W ; R_{a} ; P_{y} ; P_{z}\right),
$$

where $r$ is the radius of the workpiece; $\varepsilon$ is the eccentricity; $T$ is the depth of the defective layer; $W$ is the waviness; $R_{a}$ is the roughness of the surface; $P_{y}, P_{z}$ are the cutting force components.

Dependency analysis shows that alterations in the process system state parameters vector brings about alterations not only in the numerical values of the output variables, but also in the function that represents the object parameter transformation law.

When developing a control program, one has to evaluate the deviations in the output variables and the current state of the PS. This is why one has to develop a real-time monitoring system based on analyzing the dynamic alterations in the output variables and the process system state parameters.

To solve this problem, the authors of $[5,6]$ decomposed the PS into the following subsystems: the machine, the fixtures, and tool, the workpiece, the cooling lubricant, and the cutting process.

By analyzing the decomposition of input and output variables plus the subsystem state parameters, one can identify the most significantly altered parameters in each subsystem to evaluate their effect on the output variables of clean-grinding.

Consider the specifics of how state parameters and output variables alter in a grinding operations; for such analysis, we use Yu. Tu's classification [7]. Intervals of the alterations in interrupt times $T$ of the parameters of a process system consists of longer (higher-order) interrupt periods include several intervals of the sub-order. The intervals are structured in a hierarchy. For instance: when machining parts type shaft using a wheel-grinding machine, it was found that the time machine maintenance $T_{\text {ст }}=7.5 \times 10^{6} \mathrm{~s}$., time complete tool wear $T_{\text {ин }}=6.9 \times 10^{4} \mathrm{~s}$., time to tool dressing $T_{\text {пр }}=2.4 \times 10^{2} \mathrm{~s}$, time to process a single surface $T_{\text {пов }}=20 \mathrm{~s}$., time to rotate the part $T_{\text {обд }}=0.25 \mathrm{~s}$., time to rotate the wheel $T_{\text {обкр }}=0.026 \mathrm{~s}$. These intervals are not constant and depend on the structural specifics of the system components, the control effects alterations law, and the state of the system at time $t$. Alterations in the subsystem parameters alter the output variables $y$ by $\Delta y$.

After an interrupt in cutting, the parameters of the system or its subsystems are partially or fully restored (workpiece replacements, wheel dressing, tool or fixture replacement). As a result, the output variables $y$ (material removal rate at the beginning of the next cycle alters by $\Delta(\Delta r)$, the roughness of the material at the beginning of the next cycle alters by $\Delta R a$.

By generalizing the experience with gringing machines and the analyzsis above, we conclude that controlling the output variables $y$ at time $t$ does not enable the identification of the process system state parameters, the alterations of which cause deviations in the output variables. Such identification is enabled by controlling the alteration rate of $y(t)$ as the intervals of interrupt times $T$ are considerably different for different subsystems [8].

Simulate the grinding state space.

We know the models for: a continuous system

$$
\begin{gathered}
\dot{z}(t)=A(t) z(t)+B(t) U(t) \\
y(t)=D(t) z(t)
\end{gathered}
$$

a discrete system

$$
\begin{gathered}
z(t)=A(t) z(t-1)+B(t) U(t) \\
y(t)=D(t) z(t)
\end{gathered}
$$

where $z(t)$ is the vector of the process system state parameters; $U(t)$ is the vector of control effects;

$A(t), B(t), D(t)$ are the matrices of the corresponding coefficients.

Kalman filters can be built to evaluate the process system state parameters based on the dependencies (2-5), whereas Kalman-Bucy filters can be used in case of significant errors in output variable and perturbation measurements [9]. When monitoring the system herein described, building such filters can be difficult as the vectors of control effects in (2) and (4) depend on the system state parameters; at any stage, they are 
determined by the optimum control method, e.g. when calculating the limit cycle for maximum performance. Besides, most dependencies that simulate the machining process are non-linear. When building a filter, matrices $A$ and $B$ are considered known whereas they have yet to be determined in diagnosing. Dependencies (2) and (4) do not contain system restoration data either. To factor in the restoration option for the process under analysis, rewrite the equations (4) and (5) as:

$$
\begin{gathered}
z_{i, j}(\tau)=z_{i j-1}+A_{i j}(j-1)+A_{z i j}\left(\tau-\sum_{k=1}^{j-1} \tau_{u k}\right), \\
y_{i}(t)=D_{i}(t) z_{i}(t) \\
\dot{y}_{i}(t)=D_{i} \dot{z}(t)
\end{gathered}
$$

where $A_{i j}$ is the operator that factors in the restoration of the $i$ th parameter of the system upon completing the $(j-$ 1)th cycle (i.e. before the $j$ th cycle); $A_{z i j}$ is the operator that determines the alterations in the system parameter in the $j$ th cycle; $\tau_{u k}$ is the time to complete the $k$ th cycle.

Besides, the system should be complemented with a procedure to find out whether the output variable alterations rate belongs to the alteration intervals $y_{1}(t)$, $\mathrm{y}_{2}(\mathrm{t}), \ldots \mathrm{y}_{\mathrm{m}}(\mathrm{t})$ of this or that interruption period:

$$
\dot{y}(t) \in\left[\begin{array}{l}
\dot{y}_{1}(t) \\
\dot{y}_{2}(t) \\
\cdots \\
\dot{y}_{m}(t)
\end{array}\right]
$$

By analyzing the dependencies (6) to (9), we can conclude that if the ratios in (9) allows one to identify the altered process system state parameter, we can find the value of this parameter based on the output variable value at any time.

Restoration and PS state parameter alteration operators in the equation (6) can crucially depend on the number of the current cycle. In grinding operations, wheel dressing (i.e. restoring its applied surface) can be carried out after machining a single workpiece or a batch of workpieces. Such restoration is not always complete. For instance, if we machine ten parts and then dress the cutter (i.e. make adjustments in the number of cutting edges, their distribution over the depth of the layer, or their protrusion above the bond), the wheel becomes 1 to 2 millimeters less in radius. This reduces the cutting speed by 0.2 to 0.5 percent. This may seem insignificant; however, we should take into account that before a wheel is worn out, it machines 1000 to 3000 parts and has its radius halved from $400 \mathrm{~mm}$ to $200 \mathrm{~mm}$. This correspondingly halves the cutting speed.

We also have to evaluate the alterations in the uncontrollable process system state parameters that may occur when restoring its components and subsystems, i.e. during machine and fixture maintenance, tool replacement or dressing.

$$
\begin{aligned}
\Delta y_{j} & =y_{j}-y_{j-1} ; \\
\Delta z_{j} & =D \Delta y_{j} .
\end{aligned}
$$

State space analysis can be employed to describe the behavior of the grinding system. Consider how it could be applied to study the processes herein analyzed. To link the sequential states of the system in time, assume that the derivative of the state vector at time $t$ depends on its current state rather than pre-development. This enables us to describe the process by a vector-matrix differential equation:

$$
z^{\prime}(t)=f[z(t), U(t), t],
$$

where $z(t)$ is the vector of the process system state parameters; $U(t)$ is the vector of control effects; $f$ is the vector function of state variables.

For an interval of $\tau$, the differential equation (11) for a non-standard discrete system is written as:

$$
\frac{d V(\lambda)}{d \lambda}=A V(\lambda)
$$

where $A$ is the extended system coefficient matrix;

$$
\lambda=t-n T \text { and } 0<\lambda \leq T
$$

$V(\lambda)$ is the column vector of the input variables $m_{i}$ and the parameters $z_{j}$ of the system

$$
\begin{aligned}
& V(\lambda)=\left[\begin{array}{c}
m(\lambda) \\
z(\lambda)
\end{array}\right] ; \\
& m(\lambda)=\left[\begin{array}{c}
m_{1}(\lambda) \\
m_{2}(\lambda) \\
\vdots \\
m_{n}(\lambda)
\end{array}\right] ; \\
& z(\lambda)=\left[\begin{array}{c}
z_{1}(\lambda) \\
z_{2}(\lambda) \\
\vdots \\
z_{k}(\lambda)
\end{array}\right] .
\end{aligned}
$$

The equation (12) is solved as follows:

$$
V(\lambda)=\Phi(\lambda) V\left(0^{+}\right)
$$

where $\Phi(\lambda)$ is the transition matrix defined from (14) by replacing $\lambda$ with $0^{+} ; V\left(0^{+}\right)$is the initial conditions vector, written as:

$$
\Phi(\lambda)=L^{-1} / s I-A \digamma^{-1}
$$

where $L^{-I}$ is a inverse Laplace transformation; $I$ is an identity matrix.

In terms of the variable $t$, the equation (17) is written as: 


$$
V(t)=\Phi(t-n T) V\left(n T^{+}\right) .
$$

By making substitutions in (19) $V\left(n T^{+}\right)=B V(n T)$, where $B$ is an initial conditions matrix, and introducing $H(t-n T)=\Phi(t-n T) B$, we finally obtain

$$
V(t)=H(t-n T) V(n T) .
$$

Consider the sequential states of the system at $n=0$; $n=1 ; \ldots n=n-1$; direct and inverse $Z$-transformation results in the general system state equation solution:

$$
\left.V(n T)=Z^{-1} / I-z^{-1} H(T)\right)^{-1} \cdot V(0) .
$$

By generalizing the equations (21) for a discrete system with a main interrupt period and a higherfrequency interrupt, we obtained the dependency [5]

$$
V(t)=\Psi(t-n T) V(n T),
$$

where $\Psi(t-n T)$ depends on the recurrent ratio

$$
\Psi_{i}(t-n T)=H_{i}\left(t-n T-t_{i}\right) H_{i-1}\left(t_{i}-t_{i-1}\right) \ldots H_{1}\left(t_{2}-t_{1}\right) H_{0}\left(t_{1}\right),
$$

where $T$ is the duration of the main interrupt period; $t_{1}$, $t_{2}, \ldots, t_{i}$ are the varying durations of higher-frequency interrupt intervals.

The dependency (22) enables a complete description of how the system behaves at any interval of the main period. It is convenient for modern computing as it involves a sequenced solution of the system in the space of the time $t$.

Consider the application of the ratio (22) to the process under analysis. If $T_{1}, T_{2}, \ldots, T_{N}$ stands for the interrupt intervals in ascending order, a generalized dependency for the current time $t$ can be written as a system:

$$
\left.\begin{array}{l}
V(t)=\psi_{N}\left(t-n_{N} T_{N}\right) V\left(n T_{N}\right) \\
\psi_{N}\left(t-n_{N} T_{N}\right)=H_{i}\left(t-n_{N} T_{N}-t_{i}\right) H_{i}\left(t_{i}-t_{i-1}\right) \\
\psi_{N-1}\left(t-n_{N} T_{N}-T_{N-1}\right)=\ldots
\end{array}\right\}
$$

\section{Conclusion}

Thus, to improve the efficiency of the monitoring system based by dynamic alterations in the output variables and the process system state parameters, we have to:

- classify the alterations in the process system state parameters;

- establish functional or statistical links of the output variables to the alterations in the process systems state parameters.

The proposed state space analysis method enables an independent evaluation of output perturbations. Besides, by analyzing the dependencies we had obtained, we concluded that for such evaluation, one would have to calculate not only the absolute values of output variables, but also their first and sometimes even second derivatives.

The analysis of such behavior is reduced to sequential calculation of its parameters at times $t_{1}, t_{2}, \ldots$, $t_{i}$ at interrupt intervals $T_{1}, T_{2}, \ldots, T_{N}$. The solution can be simplified by means of parallel programming by viewing the multidimensional system as a total of $n$ onedimensional systems.

\section{References}

1. A.V. Korolev, Yu.K. Novoselov, Theoretical and probabilistic fundamentals of abrasive processing. Part 1. State of the working surface of the abrasive tool (Saratov: Izdatel'stvo Saratovskogo universiteta, 1987)

2. Yu.V. Petrakov, O.I. Drachev, Teoriya avtomaticheskogo upravleniya tehnologicheskimi sistemami (M.: Mashinostroenie, 2009)

3. Yu.K. Novoselov, Dynamics of surface shaping in abrasive processing (LAP LAMBERT Academic Publishing. - Saarbrucken, Deutschland, 2017)

4. A.A. Ignatev, M.V. Vinogradov, V.V. Gorbunov, Monitoring stankov $i$ protsessov shlifovaniya $v$ podshipnikovom proizvodstve (Saratov: SGTU, 2004)

5. Yu.K. Novoselov, E.E. Yagyaev, N.R. Kirienko, Diagnostika operatsiy chistovogo shlifovaniya po dinamike izmeneniya vyihodnyih peremennyih $i$ parametrov sostoyaniya tehnologicheskoy sistemyi, Vestnik Sevastopolskogo natsionalnogo tehnicheskogo universiteta: sbornik nauchnyih trudov, V 107. pp.170-173 (2010)

6. E.E. Yagyaev, L.B. Shron, Diagnostika processa shlifovaniya po dinamike izmeneniya vyhodnyh peremennyh, Technologiai Automatyzacja Montażu - zespołów, maszyniurządzeń. Nr 2(80), pp. 53-57 (2013)

7. Y. Tu, Sovremennaya teoriya upravleniya (M.: Mashinostroenie, 1971)

8. R. Dorf, R. Bishop, Sovremennye sistemy upravleniya [transl. by B.I. Kopylova] (M.: Laboratoriya bazovyh znanij, 2002)

9. S.M. Bratan, Quality assurance and improving processing stability during the finishing and fine grinding, Cutting \& tool in technological system. International Scientific-Technical Collection, Edition 68. pp. 34-39 (2005) 